\title{
Study of Green IT: Present to Future
}

\author{
Jasvinder Kumar \\ Assistant Professor (IT) \\ SGTBIM\&IT College \\ (Affiliated to GGSIPU)
}

\author{
Harneet Kaur \\ Assistant Professor (IT) \\ SGTBIM\&IT College \\ (Affiliated to GGSIPU)
}

\begin{abstract}
The exponential growth in users of computer over the years has impacted environment drastically. A primary concern of this paper is to study the transformation of computer state from grey to green. Green IT is basically referred to Green computing this study shows how the emerging green technology reduces the negative impact of computing on the environment. The goal of green computing is simple: reduction in the use of harmful materials, maximizes energy efficiency, and promotes recyclability. The idea is to ensure the least human impact on the environment. 'Green Computing 'has moved research into energy-saving techniques from home computers to enterprise systems' Client and Server machines. Saving energy or reduction of carbon footprints is one of the aspects of Green Computing. The research in the direction of Green Computing is more than just saving energy and reducing carbon foot prints. This study provides a brief account of Green Computing. Here, the concept of green computing and its core ideals in detail, including what it is, why it's needed and some ideas for the future has been discussed.
\end{abstract}

\section{General Terms}

Energy Star, Environment, Green computing, Recycle, Sustainable, Green IT, e-waste recycling.

\section{Keywords \\ HPC, CO2, ICT, EPA, ACPI.}

\section{INTRODUCTION}

Green computing is the methodology to use energy efficient technologies, techniques and devices with the aim to save environment from harmful effects of traditional computing. Along with this, another important aim is achieved, that matters to each individual and industry cost is saved. Green computing, the study of efficient and eco-friendly computing resources is under the attention of environmental organizations, and businesses from other industries.[1] It start from design to manufacturing to use of equipment and then safely disposing-off computers, related devices, networking and communications equipments efficiently and effectively with negligible or no impact on the environment. Today special attention is being given by researchers and professionals to minimize e-waste and use of Non-toxic materials in preparation of e-equipments. Energy efficiency is increasingly important for future ICT (Information and Communication Technologies) as the cost and availability of energy is rising day by day. The increased usage of ICT with increasing energy costs and the need to reduce greenhouse gas emissions demand for energy-efficient technologies .The very first and most conclusive research showed that $\mathrm{CO} 2$ and other emissions are causing global climate and environment a huge damage. [2] Therefore it is at the top most priority and challenge for Green Computing technologist to preserve our beloved planet. This paper is organized as follows: section-1 give Introduction next, section 2 provide brief history, section 3 reviews current trends in the field of Green Computing; section 4 will explore the challenges of Green
Computing; section 5 will discuss the future trends towards Green Computing; and finally section 6 summarized the issues related to Green Computing and concludes.

\section{HISTORY OF GREEN COMPUTING}

The first step towards green computing movement was the commencement of the Energy Star program in 1992 .Which served as a voluntary label awarded to successful computer products used minimum energy and maximized efficiency. The rating was awarded to monitors, refrigerators, television sets, air conditioners, and other household appliances. $[3,4]$ the first research in green computing resulted in the Sleep mode function for computer monitors. This function allows the computer to enter standby mode after a pre-set period passes without any user activity [5]. After this, various concepts like energy cost accounting, thin client solutions, e-Waste, and virtualization were developed. The idea was to make computers friendly to environment and economy $[6,7]$.

\section{CURRENT TECHNOLOGIES}

Current trends of Green Computing are towards efficient utilization of resources. Energy is considered as the main resource and the carbon footprints are considered as the major threats to environment. Therefore, the emphasis is to reduce carbon footprints and increase the performance of Computing. $[8,9]$ There are several areas where researchers are putting lots of efforts to achieve desired results:

\subsection{Resource Saving}

Human beings are living in the world -full of resources, required in our day to day life to make life easy and comfortable .somewhere the over utilization of these resources makes environment unhealthy. Following are some ways to save our environment from hazards. [9]

\subsubsection{Power Management}

This means conservation of power used by all electrical appliances. Many appliances now come with a power saving/management feature as well. Devices with this feature automatically turn off the power or switch the appliance to a low power state when not being used. There is an underlying aspect of operating system to controlling power of hardware allowed by the Advanced Configuration and Power Interface (ACPI).In addition there are some programs which can be used to adjust voltage of CPU manually to control heat emitted and electricity consumed by the CPU. [10]

\subsubsection{Server Virtualization}

Virtualization is the consolidation of servers and systems to reduce power consumption and energy utilization. One server is used to connect too many individual computers .It leads to usage of more than one system on a single piece of physical hardware. This allows minimum power consumption and maximum cooling. Centralizing the system for a group of individual users; reduces the individual hardware and space cost and saves resources if system is not in use (idle).

This development has been seen in software, technology, and other types of architecture virtualization. This step towards 
Green Computing leads to enhance computer security as well $[11,12]$.

\subsection{Green Data Centers}

One of the intense steps towards Green Computing area is maintaining Data Centers, Data Centers are those which contain a computer system itself and its associated systems for data storage. The strategy for meeting green IT directives is to avoid data duplication. Data centre can decrease the overhead concerned with holding multiple copies of the same data by identifying common data and reducing copies to a single entity [13] so it can be inferred that for a company's holding large data sets data centre plays an important role but on the other hand the increased demand of datacenters has increased the demand for power also. This can be seen in fig 1 that over the period 2000 to 2005 the demand of datacenter increased drastically and the power consumption got doubled. [14] It was predicted by EPA in 2007 that by 2010 the figures will get twice of current. The increased costs and threat of energy consumption-related taxation faced by owners and operators of data centre made the prediction to change. Worldwide data centers got increased by about $56 \%$ from 2005 to 2010 instead of getting doubled while in the US it increased by about $36 \%$ instead of getting doubled. As a result prediction for 2016 has also reduced by1000MW [14, 15].Initiatives taken to reduce the energy consumption by data centre were designing of proper heat control systems along with designing of data centers[16], load evaluation using some metric and proper information system should be set up as per the business need.[17]

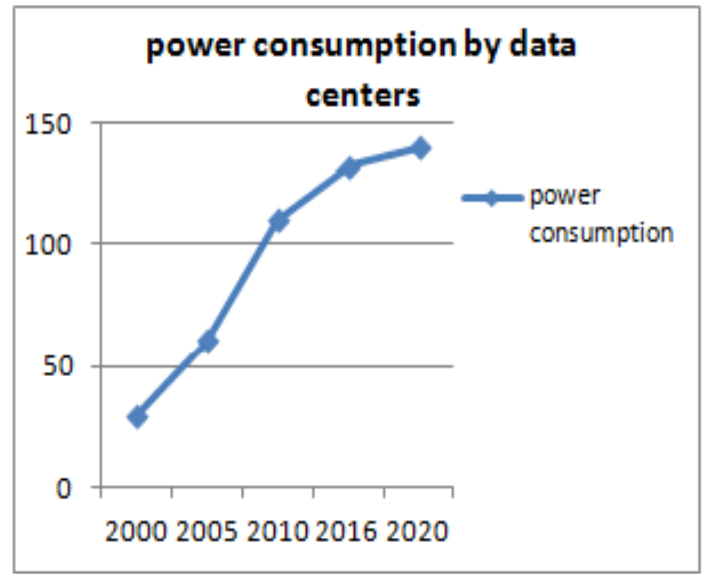

Fig-1 Showing power consumption by data centers (in Billion KW)

\subsection{Carbon-Free Computing}

One of the VIA Technologies' ideas is to reduce the "carbon footprint" of users - the amount of greenhouse gases produced, measured in units of carbon dioxide $(\mathrm{CO} 2)$. with the aim to have carbon free environment VIA has aimed to develop computers which do not emit carbon but green house gases are emitted,which can be countered by planting trees. The move towards carbon free computing enlighten another development known as solar energy cells-VIA's "pc-1" initiative aims to not just power the computer entirely through solar cells, but also use solar energy exclusively in its manufacturing process. The need of carbon free environment has made a step ahead of developing green power sources with zero carbon emissions. [18,19] Recent developments suggest the possibility of incorporating renewable energy technologies into structures in creative and unexpected ways like Sybarite's Dice House and Kennedy and Voilich Architecture's Soft House.[20,21,22]

\subsection{E-Waste Recycling}

E-waste recycling involves collection, processing, recycling, and disposal of waste materials. Reusing products is much better than letting them stay in landfills. Over 133,000 PCs are discarded by U.S. homes and businesses every day by Gartner estimations and less than 10 percent of all electronics are recycled $[23,24]$. The life cycle of product should incorporate one more phase in its life cycle that is the recycling phase of product. Every nation around the world is focusing towards recycling programs and seeking help from the companies to install and manage recycling hubs. This is easy to adopt the practice of recycling the E-Waste as it help in green environment as well as reduces the cost and time of manufacturing the new equipment again. [25]

\subsection{Solar Computing}

While walking on the path of growing IT infrastructure the need of electricity has also increased. To meet the increased demand the coal and other fossil fuels are burnt, which are emitting high carbon content in the environment .To overcome these issues Solar energy can be used as an alternative energy. The objectives of solar energy are as follows:

- It makes environment sustainable by reducing environmental pollution (i: e; carbon emission).

- It Utilizes sun heat as renewable source.

- It is used to provide electricity in remote areas and while travelling at high altitudes.

- Saves electricity cost in long run.

This initiative of using sun as the power supply has been made by VIA. For the purpose, VIA partnered with Motech Industries has taken initiative for using solar energy by manufacturing solar cells worldwide which are nonpolluting and highly reliable. Solar cells require less maintenance cost throughout their lifetime. As part of VIA's "pc-1" initiative, the company established the first-ever solar-powered cyber community center in the South Pacific, powered entirely by solar technology [26].India has biggest contribution in solar power generation ,It has planted World's largest solar plant in Madhya Pradesh will be generating $750 \mathrm{MW}$ power, will be completed by 2016 [27]. The more green gadgets are available in the market such as solar Power Bags for Laptop and Gadget Charging These include the Voltaic Generator Solar Laptop Charger, PREPARED.PRO Solar Laptop Bag, and Solaria Solar Laptop. [28]. Thinvent solar computers are currently used to provide computing facility in remote area as they require DC power supplied by Thinvent DC-UPS capable of charging storage batteries from solar panel [29]

\section{CHALlenges}

In past traditional computing practices the focus was on computing efficiency and cost associated to IT equipments and infrastructure services. To accommodate all the needs of an IT industry, the demand for great infrastructure is growing day by day which is also leading towards growth of global warming. This is further becoming an issue for researchers to get with something which can help IT industries as well as sustain the environment healthy. So to cool down the growing glob warming researches are developing cooling systems. At one shore processing power is important to business and on the other shore it is the drive, challenge of environment 
friendly system, and infrastructure limitations this is a challenge for researches to accommodate not only IT equipment users as well as IT equipment vendors. The researchers at vendors side have made considerable progress in this area, In 2005, the company introduced the VIA C7-M and VIA C7 processors that have a maximum power consumption of $20 \mathrm{~W}$ at $2.0 \mathrm{GHz}$ and an average power consumption of $1 \mathrm{~W}$. These energy-efficient processors produce over four times less carbon during their operation [30].

According to researchers of Green Computing following are few prominent Challenges that Green computing is facing while implementing the green solutions:

- Load balancing is the main challenge in cloud computing that is to distribute the workload across multiple nodes while ensuring no single node is overwhelmed. Minimize the resource consumption further reduce energy consumption and carbon emission.[31]

- $\quad$ Best Solar energy panel efficiency is still 35\% i: e; to convert sunlight into electricity and its difficult to have solar energy at all times for e.g.: in cloudy days and at night times.[32]although solar energy is free but to capture that energy is very expensive.

- Government initiative requires installing cooling systems and governing energy utilization.

- Amount of power consumption by data centers is an issue along with the cost of increasing data storage space.

- Governing bodies need to check Disposal of Electronic Wastes.

- Greenness of Software: metric is required to check greenness of software.

\section{FUTURE TECHNOLOGIES \\ 5.1 Eco Friendly Components}

Several PC manufacturers already use the more sustainable and less toxic recycled plastics and bio-plastics in their tower and monitor casings. HP uses a biodegradable corn-based plastic case in its printers. Other companies use wood and bamboo wood-encased desktops in computer towers, monitors, and mouse controls. While most manufacturers have eliminated CRT monitors that emit toxic radiation, the replacement LCD screens are not completely free of toxic materials.[33] as the more energy efficient and toxic-free OLED technology becomes advanced and cost effective, OLED monitors could replace LCD screens as the industry standard. E-ink and IMOD are two other monitor-related technological breakthroughs that have the potential to have a significant impact in future green technology.[22]

\subsection{VIA Technologies Green Computing}

In 2001 VIA Technologies, Taiwanese company manufacturing computer hardware, introduced its initiative for "green computing" by focusing on power efficiency through the design and manufacturing process of its products. Its environmental friendly products are manufactured using a range of clean-computing strategies, and the company is striving to educate markets on the benefits of green computing for the sake of the environment.

As per the interview of Gaynor de Wit, the future vision of VIA will continue to innovate in the $\mathrm{x} 86$ platform spaces and push forward more power-efficient, smaller-form-factor components. They will also work with organizations and companies involved with renewable energies in an effort to develop more sustainable computing platforms. They believe in connecting us to the world through information technology using renewable energy. [26]

\subsection{Green Computing: A Dual Technology for Cloud Computing and HPC (High performance computing)}

As demand for computing and communication continues, the need for power to drive individuals' computer systems also grows. To fulfill the requirement of communication a technology named cloud computing is introduced $\mathrm{i}$ : e; which outsource all the needs of IT through a server over a large network. On the other hand, complicated processes need exascale computing for modeling and simulation. These contemporary technologies are moving towards intelligent computation, in order to optimize resource and energy consumption without losing performance HPC is introduced. HPC and cloud computing provides solutions for green computing and climate change but, As the no of shared resources such as( servers, networks, and data centers) increased, the amount of consumption of energy and $\mathrm{CO}_{2}$ also increase. For efficient communication and computing green solutions are required. So it is inferred that these technologies are dual in nature. [12]

Cloud computing and HPC technologies are used for the betterment of industries and business growth as well as they are contributing in greenness of environment ,but a special care has to be taken on balancing their impact on power utilization while taking care of high performance. The objective of greenness in HPC is to meet through advanced task management tools (high and low level schedulers) and frameworks, smarter applications, efficient programming and reconfigurable compilers. [34, 35]

\subsection{Go Green with NComputing Desktop Virtualization and Eco-Friendly Computing.}

Globally, it is estimated that there will be more than three billion PCs in use by 2020 . With this trend, the consumption of power and carbon emission will also grow; to tap this something needs to be change.

Today world is in the generation of powerful PC's, to utilize this excess power in one PC, it can be shared with many users. This concept is called NComputing.

NComputing solutions save $75 \%$ on hardware and reduces energy footprint by $90 \%$ per user as it draw less than 5 watts of power and generate few ounces of e-waste.

If NComputing systems were used at a ratio of 6 NComputing devices to each PC:

- Energy use would decline by over 143 billion kilowatt hours per year

- CO2 emissions would decrease by 114 million metric tons. That's like planting 550 million trees [36].

\subsection{Refusal -Say No to Plastic}

When it comes to plastics, recycling may not be enough to take care of the problem. Another practice of Refusing: Refusal needs to be incorporated. Only about $7 \%$ of plastics generated in the US are recycled. Further the trend followed to recycle the E-waste or plastic is also a question i:e; 
recycling should be done in healthy way rather than hazardous way. [37] Refuse is an alternative solution, if recycling is not a practical answer, the only way is to behave sustainably and flatly refuse to purchase plastic materials designed to be almost instantly thrown away.

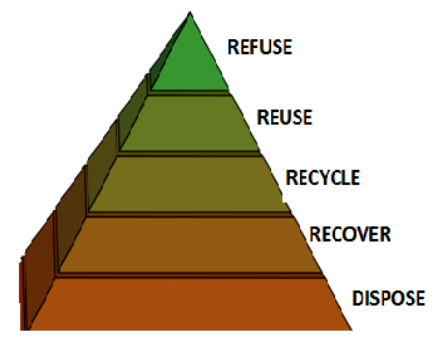

Fig 2: Stages of green product practices

\subsection{Green Practices}

\subsubsection{Going Green at Work}

Organizations all over the world are beginning to understand their corporate social responsibility towards the environment. In fact, in many organizations, the need for green computing is put at the top of the agenda. Organizations must follow these simple steps for creating the green computing awareness in their workplaces.

- Announcing green intentions to all employees.

- Setting up a committee to form a green IT plan.

- Centralization of all desktops.

- Using efficient computer applications.

- $\quad$ Power management tactics.

- Business performance enhancement.

- Paper free environment

\subsubsection{Green Labs}

Some basic practices in education system can encourage the coming youth to be environment friendly, like switching off the systems and peripherals when not in use. Reduce the utilization of computers in terms of time without effecting productivity. One should make a habit of working in a group while learning. Peripherals in labs should be environment near and dear like instead of CRT monitors OLED screens should be installed. [38]

\subsubsection{Telecommuting}

Employees working from home help in reducing carbon emission by vehicles. Moreover, it reduces cost overheads of vehicles usage and maintenance. [9]

\subsubsection{Buy Best}

At each level one should take responsibility of buying and installing best products for environment that later on effects our own self, following are some recommendations for purchasing peripherals:-

\section{- Flat OLED Monitors}

-Energy Star monitors and printers.

-inkjet printers should be purchased instead laser printers.

-buy non-petroleum based Ink.

\subsection{Developments in Energy Efficiency}

The future green technology holds big advancements in shaping energy efficient computers.

The new Energy Star 4.0 specifications include the 80 PLUS standards that encourage manufacturers to deploy power supplies that convert at least 80 percent of the electricity from the wall outlet to actual computing power. [3]

Intel's Core 2 Duo processor heralds a new era in green computing. This processor draws power only for the parts of the chip actually in use. Marvell's processor chip uses power factor correction (PFC) to determine the amount of power any given application requires and uses this information to optimize power usage for maximum efficiency.[39]

Such power-saving technologies are poised to become the norm in the future, and further advancements will bring forth more breakthroughs.

The development of nanotechnology also translates to greater energy efficiency. The future Nano computer chip would be three or four levels of magnitude smaller in size and considerably faster than the ones currently available.

Another revolutionary idea that could find breakthrough in the future is harnessing the power needed for the computer to operate from keystrokes, mouse movements, and the light from the monitor. [9]

\subsection{Government Green Policies}

The major fillip to the contemporary advancements in green technology is two directives of the European Union:

1. The 2003 Restriction on Hazardous Substances (RoHS) directive restricted the use and selling of electronic equipments if it contains Six types of hazardous substance like lead, cadmium, mercury etc exceeds the agreed level of $0.01 \%$.[40]. Another directive WEEE (Waste Electrical and Electronic Equipment) regulates E-Waste properly by using a take back system where the use products are returned by the consumer to manufacturers for recycle purpose.[41]

2. The 2007 Registration, Evaluation and Authorization of Chemicals law $(\mathrm{REACH})$ that bans some hazardous chemicals and mandates permission from the European Commission to use other toxic chemicals.[42]

3. India also has initiated few steps under NAPCC (National Action Plan on Climate Change) to implement Green IT.[43]

The electronic industry has still not witnessed the full impact of RoHS and REACH as research is still ongoing for alternatives to all toxic substances. The future, however, is sure to witness the emergence and widespread use of ecofriendly and energy efficient computers completely free of all harmful toxic elements.

\subsection{Green Metrics and Methodology}

Software contributes great effect on the environment just as hardware, so to evaluate the greenness and energy efficiency metrics should be developed. Software tools can be built to keep track of amount of energy utilized, heat emitted and how the underlying hardware is utilized. Tools available to check the resource utilization can act as an aid in having software product green. This process should be embedded with software life cycle from requirement to disposal phase, as a positive step towards sustainable development. [45 
Following steps can be incorporated in software engineering process, irrespective of the development process -sequential, iterative or agile.[46]

-Identify the sustainability using green guidelines at each phase.

- evaluate relevant metrics to measure greenness. -adopt appropriate approaches to make software product green. These steps help in building sustainable environment.

\section{CONCLUSION}

With a view to make environment green and healthy, every computer user at personnel or industry level should step ahead to save environment. Green technology is gaining more and more public attention through the work of environmental organizations and government initiatives.

Future trends are also using computers and Living Machines such as the one developed by Worrell Water Technologies, where entire buildings and even municipalities can recycle wastewater for continuous use - all controlled by specially designed computers with a goal toward saving on another precious resource: water[46]. Going green is not as easy as it seems. It requires careful planning, doing one thing at a time, making trade-offs, and factoring in regulatory considerations besides adopting energy-efficient tips, recycling, and more. The most effective green strategies are those which extend to the complete product life cycle, such as marketing, and remain sustainable. It is important to quantify sustainability and environmental performance to help reach our goals.

As concerns of environment degradation grows, the future of green technology is sure to witness legislation and regulations that make green computing mandatory rather than optional. Side by side, further developments in technology, especially carbon free computing and advancements in recycling technology, will make green computing even more beneficial and cost-effective. These green computing tips allow users to save even more power and money.

\section{REFERENCES}

[1] http://www.greencomputing.co.in

[2] http://en.wikipedia.org/wiki/Green_Computing

[3] Energy star. http://www.energystar.gov/, 2011

[4] Department of Energy, Annual Energy Review 2008.http://people.virginia.edu/_gdc4k/phys111/fall09/i mportant documents/aer 2008.pdf.

[5] Daniel P. Dern. Power plug meters help save money, energy. Computerworld.http://www.computerworld.com.

[6] Power Management Software Helps Slash Energy Costs. http://www.windowsitpro.com/article/news2/powermanagement-software-helps-slash-energy-costs.aspx, 2008 .

[7] http://timesofindia.indiatimes.com computing.

/topic/Green-

[8] S.V.S.S Lakshmi,Ms. I Sri Lalita Sarwani,M.Nalini Tuveera"A study on Green Computing: The Future Computing and Eco Friendly Technology", International Journal of Engineering Research and Application(IJERA), Vol. 2, Issued4,July-August 2012.

[9] www.brighthub.com/enviornment/greencomputing/articles/42712.aspx.
[10] Shalabh Agarwal and Asoke Nath:" Green Computing - a new Horizon of Energy Efficiency and Electronic waste minimizationll: a Global Perspective, Proceedings of IEEE CSNT-2011 held at SMVDU (Jammu) 03-06 June 2011, Page 688-693.

[11] Shalabh Agarwal and Asoke Nath, ,'Desktop Virtualization and Green Computing Solutions", The Second International Conference on "Soft Computing for Problem Solving published in the proceedings of the conference SocPros 2012 held in December 28 - 30, 2012 and will be published in Conference proceedings in AISC series of Springer.

[12] Shalabh Agarwal, Asoke Nath "Cloud Computing is an application of Green Computing - a new horizon of Energy Efficiency and its beyond" proceedings of International conference ICCA 2012 held at Pondicherry Jan 27-31, 2012.

[13] Dietrich, J., et al. "The Green Data Center." IBM Global Services (2007): 1-20.

[14] Jonathan G. Koomey, Ph.D. Consulting Professor, Stanford University "GROWTH IN DATA CENTER ELECTRICITY USE 2005 TO 2010" A report by Analytics Press, completed at the request of The New York Times

[15] Forrest, William, James M. Kaplan, and Noah Kindler. "Data centers: how to cut carbon emissions and costs." McKinsey on business technology 14.6 (2008).

[16] Bailey, M., et al. "Special Study: Data Center of the Future." (2007).

[17] Mitchell, R. L. "Power pinch in the data center." ComputerWorld (2007).

[18] www.via.com.tw/en/initiatives/greencomputing.

[19] http://en.wikipedia.org/wiki/Green_Computing

[20] www.tuvie.com/extraordinary-dice-house-from-cyber

[21] www.architectmagazine.com/architects/kennedy-violicharchitecture.aspx

[22] TheFutureOfThings.com. Green Computing Walker, Tom. 7 Green Technologies of the Future

[23] Dianna Cohen Though Truths About Plastic Recyclinghttp://www.ted.com/talks/dianna_cohen_tough_truths_ab out_plastic_pollution.html.

[24] 2013Where does e-waste end up? Green Peace International Feb 242009.

[25] Hanselman, Scott E., and Mahmoud Pegah. "The wild wild waste: e-waste." Proceedings of the 35th annual ACM SIGUCCS fall conference. ACM, 2007.

[26] www.via.com.tw/en/initiatives/greencomputing.

[27] Report in "The Times of India", Student edition, Feb2015,page-1.

[28] http://www.en.wikipedia.org/wiki/solar_energy/info

[29] www.thinvent.in/solar/

[30] www.via.com.tw/en/initiatives/greencomputing

[31] Nidhi Jain Kansall , Inderveer Chana" Cloud Load Balancing Techniques : A Step Towards Green Computing" IJCSI International Journal of Computer 
Science Issues, Vol. 9, Issue 1, No 1, January 2012 ISSN (Online): 1694-0814 www.IJCSI.org

[32] http://solarenergy.net/News/3-challenges-solar-energyneeds-overcome-continue-growth/] May 19, 2014.

[33] http://www.wipro.in/products/greenpc/index.html.

[34] Goran Martinovic, Zdravko Krpic "Towards Green HPC Blueprints", CLOUD COMPUTING 2011 : The Second International Conference on Cloud Computing, GRIDs, and Virtualization, IARIA, 2011. ISBN: 978-1-61208153-3.

[35] http://www.computer.org/web/computingnow/archive/se pt-2012”- :IEEE society

[36] http://www.ncomputing.com/company/green-computing

[37] Mike Biddle A Better Wayto Recycle Plastics http://blog.ted.com/2012/10/22/a-better-way-to-recycleplastics.

[38] Shalabh Agarwal, Kaustuvi Basu, Asoke Nath , Bidhusundar Samanta "Green Computing and Green Technology based teaching learning and administration in Higher Education Institutions", International Journal of Advanced Computer Research, Vol-2, Number-3, issue-11, Sept, pp 295- 303(2013).
[39] Lawton, George. "Powering down the computing infrastructure." Computer40.2 (2007): 0016-19.

[40] The 5 Gyres Institute what is the Solution http://5gyres.org/what_is_the_solution.

[41] www.rhos.gov.uk

[42] www.weeeregistration.com

[43] www.climatesaverscomputing.org

[44] Government of India ministry of Environment and Forests, "National mission for Green India", New Delhi,26 ${ }^{\text {th }}$ March 2011, available at: www.naeb.nic.in access on 12 May 2011.

[45] Sara S. Mahmud and Imtiaz Ahmad" A Green Model for Sustainable Software Engineering", International Journal of Software Engineering and Its Applications Vol. 7, No. 4, July, 2013.

[46] S. Naumann, M. Dick, E. Kern and T. Johann, "The GREENSOFT Model: A reference model for green and sustainable software and its engineering", Sustainable Computing: Informatics and Systems, vol. 1, no. 4, (2011), pp. 294-304.

[47] Worrell Water Technologies -How Living Machines Work 